\title{
Development and Clinical Evaluation of New Topical Anesthetic Formulations for Dental Care
}

\author{
Takahito Ando, ${ }^{a, b ;}$ Yoshiaki Shimoo, ${ }^{c}$ Masayoshi Nakasato, ${ }^{c}$ and Hisahiro Yoshida ${ }^{*, b}$ \\ ${ }^{a}$ Department of Pharmacy, Yurin Hospital; 2-15-38 Funabashi, Setagaya-ku, Tokyo 156-0055, Japan: ${ }^{b}$ Department \\ of Drug Metabolism and Disposition, Meiji Pharmaceutical University; 2-522-1 Noshio, Kiyose, Tokyo 204-8588, \\ Japan: and ${ }^{c}$ Malo Clinic Tokyo; FUKUHARA GINZA 8F, 7-8-10 Ginza, Chuo-ku, Tokyo 104-0061, Japan. \\ Received May 1, 2015; accepted November 19, 2015
}

To provide safe dental care, it is important to minimize the pain associated with the initial injection of the local anesthetic. For this purpose, a topical anesthetic is preliminarily applied to the area where a needle will be inserted in a clinical setting. In this study, we prepared new topical anesthetic formulations with favorable intra-oral retentivity and an excellent anesthetic effect, and clinically evaluated their efficacy. We used $4 \%$ lidocaine solution as an anesthetic drug and gelatin, agar, and a food thickener as a base to prepare new topical anesthetic formulations. The subjects rested in a supine position on a chair for dental practice prior to the following experiments. Firstly, about $0.2 \mathrm{~g}$ of the sample was applied at a test site. One minute later, the sample was removed, and a $30 \mathrm{G}$ dental injection needle was inserted into the test site. The agar/ gelatin-based formulation containing gelatin of $2 \%$ and agar of $1 \%$ had a moderate solidity at $25^{\circ} \mathrm{C}$ and a moderate fluidity at $37^{\circ} \mathrm{C}$. This formulation showed a significantly greater depth than any of the commercially available topical anesthetics. The results of the present study demonstrated that the agar/gelatin-based formulation showed an excellent analgesic effect against pain associated with needle insertion.

Key words topical anesthetic; lidocaine; gelatin; agar; analgesic effect; dental care

Dental care is commonly provided after local anesthesia is delivered to reduce patient stress caused by pain. However, the lower pain threshold of the oral cavity can render injection with a local anesthetic intensely painful. In addition, pain stimulation during dental care frequently causes problems such as worsening an underlying disease, increasing fear of dental care, and the development of systemic symptoms. Thus, pain associated with the initial injection of a local anesthetic should be minimized to avoid these issues and provide safe dental care. This can be achieved in the clinical setting by applying a topical anesthetic to the area around an injection site. However, the effects of commercially available topical dental anesthetics are often insufficient, because they easily disperse with salivary flow and are thus locally retained for short periods (intra-oral retentivity). Although some investigators ${ }^{1,2)}$ have attempted to improve the intra-oral retentivity of topical anesthetics, these compounds cannot completely eliminate the pain associated with the injection of a local anesthetic. If topical anesthetics could eliminate such pain, then general dental care might become completely pain-free and help to improve the QOL of patients.

The Visual Analogue Scale (VAS) and Numeric Rating Scale (NRS) are generally used to evaluate pain and analgesic effects. Regarding the analgesic effects of topical anesthetics for the oral cavity, evaluation using not only $\operatorname{VAS}^{1,3-5)}$ but also based on the depth of injection needle insertion ${ }^{6}$ ) have been reported.

In this study, we formulated and evaluated a novel topical anesthetic with a superior intra-oral retentivity and anesthetic effect. In addition, its efficacy was clinically evaluated by in-

\footnotetext{
${ }^{\dagger}$ Present address: Research Center for Practical Training of Student Pharmacist, Faculty of Pharma Sciences, Teikyo University; 2-11-1 Kaga, Itabashi-ku, Tokyo 173-8605, Japan.
}

vestigating the analgesic effect based on the depth of injection needle insertion.

\section{MATERIALS AND METHODS}

Samples New topical anesthetics were formulated using 4\% lidocaine solution (Xylocaine solution (4\%); AstraZeneca, Osaka, Japan) as the anesthetic drug, porcine-derived acidtreated gelatin AP-270 (Nippi Inc., Tokyo, Japan), agar (Japanese Pharmacopoeia standard; Ina Food Industry, Ina, Japan), and a food thickener (Neo-hightoromeal ${ }^{\circledR}$ III; Food Care Inc., Sagamihara, Japan) as a base. Controls comprised commercially available topical anesthetics, including PRONES ${ }^{\circledR}$ PASTA AROMA (Nihon Shika Yakuhin, Shimonoseki, Japan), Neozalocain ${ }^{\circledR}$ Pasta (Neo Dental Chemical Products, Osaka, Japan), Hurricaine ${ }^{\circledR}$ Liquid Dental 20\% (Sun Dental Original Co., Ltd., Osaka, Japan), Beezocaine ${ }^{\circledR}$ Jelly Dental 20\% (Bee Brand Medico Dental, Osaka, Japan), Copalon ${ }^{\circledR}$. Dental Topical Anesthetic Liquid 6\% (Showa Yakuhin Kako, Tokyo, Japan) and Xylocaine ${ }^{\circledR}$ Jelly (AstraZeneca).

Preparation of Novel Topical Anesthetics Formulations using agar and gelatin as a base were prepared as follows. Base material was dissolved by heating in purified water. The solution was mixed with an equivalent volume of Xylocaine ${ }^{\circledR}$, poured into a mold $c a$. 2-mm thick and cooled. The solidified formulation was cut into $5-\mathrm{mm}$ cubes. Formulations prepared based on a thickener (thickener-based formulations) were prepared by adding $1-4 \%$ thickener to Xylocaine ${ }^{\circledR}$ liquid and stirring at about $100 \mathrm{rpm}$ for 3-7 min. Gelatin concentrations ranged from 1 to $10 \%$ in gelatin-based formulations. Agarbased formulations included 0.5 to $2 \%$ agar and agar/gelatinbased formulations comprised 1\% agar and 1 to $10 \%$ gelatin.

Line Spread Test (LST) LST proceeded using an exclusive measurement plate positioned horizontally as described 
by the manufacturer (Saraya Co., Ltd., Osaka, Japan). A metal cylinder (diameter and height: 30 and $28 \mathrm{~mm}$, respectively) was placed at the center of a concentric circle that drained on the plate. Samples $(20 \mathrm{~mL})$ were poured into the cylinder, and left for $30 \mathrm{~s}$ at room temperature. The cylinder was then rapidly lifted vertically. Thirty seconds later, the spread of each sample over six directions on the plate was measured $(\mathrm{mm})$ five times, and the mean of the values for each direction was regarded as the LST value. This process was repeated five times per sample and means were calculated.

Stability Test of Formulations A stainless steel tray was placed in a water bath with a thermostat at $37^{\circ} \mathrm{C}$ and heated for $2 \mathrm{~min}$ before starting the experiment. Gelatin-, agar- and agar/gelatin-based formulations were placed on the tray in the bath, and the amount of time required for each formulation to melt was measured. The maximum amount of time was set at $5 \mathrm{~min}$. Each sample was measured five times and the mean was calculated for each sample.

Participants Ten healthy adults (aged 28-37 years; male, $n=7$; female, $n=3$ ) provided written consent to participate after receiving a verbal explanation of a document describing the purpose, methods and other information about the clinical study. This study proceeded after review and approval by the Ethics Review Committee of Meiji Pharmaceutical University (Approval No. 2201).

Measurement of Depth of Injection Needle Insertion After a participant rested for $10 \mathrm{~min}$ in a supine position on a horizontally positioned dental chair, the following experiment proceeded as defined by Ogasawara et al. ${ }^{6)}$ A test region was established in the lower gingivobuccal fold and simple moisture exclusion was air-sprayed onto the region. A sample was applied to the region and removed after $1 \mathrm{~min}$. In experiments with Copalon ${ }^{\circledR} 6 \%$ topical anesthetic solution for dental applications and the agar/gelatin-based formulations, one piece of sample was affixed to the test region and removed using forceps before the region was cleaned with dry gauze. About $0.2 \mathrm{~g}$ of other formulations were applied to test regions using a cotton swab, and removed with gauze after a specific amount of time. The lower lip was then pulled forward, and a 30-G dental injection needle was vertically inserted into the region between the central and lateral incisors. Needle insertion was stopped if the participant experienced pain, the boundary between the needle and oral mucosa was marked with $1 \%$ Pyoktanin Blue solution (Kanto Kagaku, Tokyo, Japan), and the needle was retracted. The distance between the needle tip and the mark measured using calipers was regarded as the depth of needle insertion. The order of test formulations and insertion sites was randomly assigned by lottery for each partici- pant, and tests were double-blind. The same dentist inserted the needle into all participants to prevent inter-operator variation. Insertion speed was standardized based on the speed applied during routine clinical practice to prevent variation among the participants.

Effects of Topical Anesthetic on Other Areas We assessed the intra-oral retentivity of the topical anesthetic by determining whether numbness, hypoesthesia, or a bitter taste developed outside the application area after $1 \mathrm{~min}$. The participants raised an arm if any of these events occurred and then the time and location of the events were recorded. The shapes of residues of agar/gelatin-based formulations in the oral cavity $1 \mathrm{~min}$ after application were assessed.

Testing Interval When topical anesthetics were tested several times in the same participant, the tests proceeded at an interval of at least one week. If any abnormal findings such as trauma or reversible mucosal lesions were found at test sites, the test was repeated at least one week after such findings had completely resolved.

Statistical Analysis All results were statistically analyzed using Bonferroni-adjusted Student's $t$-tests (LST) and Wilcoxon rank sum test (pain-inducing depth of needle insertion), and a significance level $<5 \%$ was regarded as significant.

\section{RESULTS}

Line Spread Test The influences of differences in thickener concentrations and the frequency of stirring formulations on the physical properties of thickener-based formulations were evaluated using the line spread test (LST). The LST value of the thickener-based formulation significantly decreased as the thickener concentration increased. Prolonging the stirring duration only slightly influenced LST values and changes were not significant at a thickener concentration of $3 \%$ (Table 1). Based on these findings, we set the thickener concentration at $3 \%$ and the stirring duration at $5 \mathrm{~min}$ to prepare thickener-based formulations.

Stability of Formulation Appearance We investigated the ability of thickener-based formulations to maintain their shape at $37^{\circ} \mathrm{C}$ and found that the shape was similarly maintained between room temperature and $37^{\circ} \mathrm{C}$.

The agar-based formulation was not sufficiently solidified at room temperature at an agar concentration of $0.5 \%$, but a solid shape was maintained at $\geq 1 \%$ agar. The shape of the formulation did not change when heated at $37^{\circ} \mathrm{C}$.

The gelatin-based formulation hardened at room temperature as the gelatin concentration increased, and a solid shape was maintained at $10 \%$. However, these formulations were

Table 1. Line-Spread Distance for Each Thickener Concentration (1-4\%)

\begin{tabular}{|c|c|c|c|c|c|c|}
\hline \multirow[b]{2}{*}{$\begin{array}{l}\text { Thickener concentration } \\
(\mathrm{w} / \mathrm{v} \%)\end{array}$} & \multicolumn{3}{|c|}{ Line-spread distance $(\mathrm{mm})$} & \multirow[b]{2}{*}{$\begin{array}{l}3 \text { vs. } 5 \\
\min \end{array}$} & \multirow[b]{2}{*}{$\begin{array}{l}3 \text { vs. } 7 \\
\min \end{array}$} & \multirow[b]{2}{*}{$\begin{array}{c}5 \text { vs. } 7 \\
\min \end{array}$} \\
\hline & $\begin{array}{l}\text { Mixing time } \\
3 \min \\
(n=5)\end{array}$ & $\begin{array}{c}\text { Mixing time } \\
5 \mathrm{~min} \\
(n=5)\end{array}$ & $\begin{array}{c}\text { Mixing time } \\
7 \mathrm{~min} \\
(n=5)\end{array}$ & & & \\
\hline 1 & $48.3 \pm 1.7$ & $47.1 \pm 1.4$ & $44.7 \pm 0.5$ & & $\dagger$ & $*$ \\
\hline 2 & $35.7 \pm 1.9$ & $32.8 \pm 0.5$ & $32.3 \pm 0.1$ & $*$ & $*$ & \\
\hline 3 & $27.3 \pm 1.2$ & $26.7 \pm 0.3$ & $26.8 \pm 0.3$ & & & \\
\hline 4 & $24.7 \pm 0.6$ & $22.8 \pm 0.7$ & $23.6 \pm 0.5$ & $\dagger$ & & \\
\hline
\end{tabular}

Values are the mean \pm S.D. $* p<0.05,{ }^{\dagger} p<0.01$. 
Table 2. Amount of Time Required for Agar/Gelatin-Based Formulations to Completely Melt at Different Gelatin Concentrations

\begin{tabular}{cc}
\hline \hline Gelatin concentration $(\mathrm{w} / \mathrm{v} \%)$ & $\begin{array}{c}\text { Time required to completely melt } \\
(\mathrm{s})(n=5)\end{array}$ \\
\hline 1 & $>300$ \\
2 & $>300$ \\
3 & $>300$ \\
4 & $>300$ \\
5 & $235 \pm 33.2$ \\
6 & $137 \pm 26.4$ \\
7 & $56 \pm 6.6$ \\
8 & $35 \pm 6.5$ \\
9 & $36.2 \pm 5.6$ \\
10 & $35.8 \pm 3.9$ \\
\hline
\end{tabular}

Values are the mean \pm S.D.
Table 3. Effects of Topical Anesthetic Formulations on Areas Where They Were Not Applied

\begin{tabular}{crl}
\hline $\begin{array}{c}\text { Topical anesthetic } \\
\text { formulations }\end{array}$ & Number of effects & Sites of effects \\
\hline A & $0 / 10(0 \%)$ & None \\
B & $0 / 10(0 \%)$ & None \\
C & $0 / 10(0 \%)$ & None \\
D & $7 / 10(70 \%)$ & Tongue \\
E & $10 / 10(100 \%)$ & Tongue, lip, throat \\
F & $9 / 10(90 \%)$ & Tongue, lip \\
G & $7 / 10(70 \%)$ & Tongue \\
H & $7 / 10(70 \%)$ & Tongue, lip \\
I & $6 / 10(60 \%)$ & Tongue \\
J & $10 / 10(100 \%)$ & Tongue \\
\hline
\end{tabular}

A, agar/gelatin-based formulation; B, thickener-based formulation; C, agar-based formulation; D, gelatin-based formulation; E, Beezocaine ${ }^{\circledR}$ Jelly Dental $20 \%$; F, Hurricaine ${ }^{\circledR}$ Liquid Dental 20\%; G, NEOZALOCAIN ${ }^{\circledR}$ PASTA; H, COPALON ${ }^{\circledR}$ Dental Topical Anesthetic Liquid 6\%; I, PRONES ${ }^{\circledR}$ PASTA AROMA; J, Xylocaine ${ }^{\circledR}$ Jelly.

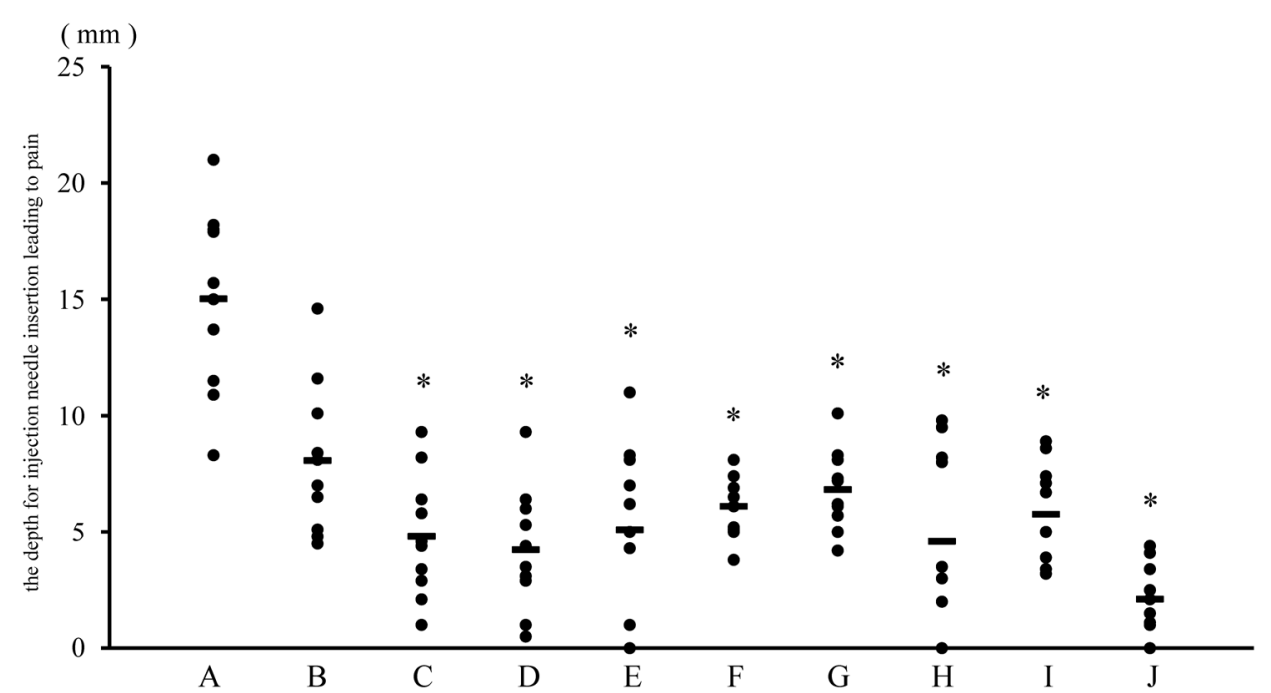

Fig. 1. Comparison of the Depth for Injection Needle Insertion Leading to Pain (*vs. Agar/Gelatin-Based Formulation, $p<0.05$ )

A: agar/gelatin-based formulation, B: thickener-based formulation, C: agar-based formulation, D: gelatin-based formulation, E: Beezocaine ${ }^{\circledR}$ Jelly Dental $20 \%$, F: Hurricaine ${ }^{\circledR}$ Liquid Dental 20\%, G: NEOZALOCAIN ${ }^{\circledR}$ PASTA, H: COPALON ${ }^{\circledR}$ Dental Topical Anesthetic Liquid 6\%, I: PRONES ${ }^{\circledR}$ PASTA AROMA, J: Xylocaine ${ }^{\circledR}$ Jelly. $^{\circ}$

melted by heating at $37^{\circ} \mathrm{C}$.

The shape of the agar/gelatin-based formulations was changed by heating, and formulations with $\geq 8 \%$ gelatin concentration completely melted within $1 \mathrm{~min}$ at $37^{\circ} \mathrm{C}$. When the gelatin concentration was $\leq 4 \%$, the formulation began to melt slightly, but not completely after heating at $37^{\circ} \mathrm{C}$ for $5 \mathrm{~min}$ (Table 2). The shape was mostly retained at a gelatin concentration of $\leq 2 \%$ even after $5 \mathrm{~min}$ at $37^{\circ} \mathrm{C}$.

Comparison of Depth of Needle Insertion Required to Elicit Pain Injection needles used to deliver agar/gelatinbased formulations could be inserted to an average depth of about $15 \mathrm{~mm}$, which was significantly deeper than those for agar- or gelatin-based formulations. In addition, agar/ gelatin-based formulations could be delivered to a significantly greater depth than any commercially-available topical anesthetics (Fig. 1). No problems developed after the test in any participants and pain did not develop after the anesthetic effect disappeared.

Local Retentivity Gelatin-based topical anesthetic formulations completely dissolved within $1 \mathrm{~min}$ of application.
In contrast, agar-based formulations did not and dispersed from the application area, resulting in less satisfactory local retentivity. The appearance of the agar/gelatin-based formulations did not change within $1 \mathrm{~min}$ after application, suggesting more satisfactory local retentivity. Furthermore, changes in the appearance of the gel formulation containing food thickener were not visually apparent and remained where they were applied. Xylocaine ${ }^{\circledR}$ Jelly was obviously dispersed $1 \mathrm{~min}$ after application.

Effects of Topical Anesthetics on Areas Where They Were Not Applied Side effects of topical gelatin-based formulations and Xylocaine ${ }^{\circledR}$ Jelly such as numbness, hypoesthesia or a bitter taste developed in areas where they were not applied within $1 \mathrm{~min}$ after injection. However, agar/gelatinand agar-based formulations did not elicit such effects (Table 3) after testing.

\section{DISCUSSION}

Commercially-available topical anesthetics for dental prac- 
tice can sufficiently numb the mucosal surface. However, pain associated with drug injection is considered to result from abrupt swelling of the tissues around the injection area. ${ }^{2)}$ Accordingly, topical anesthetics need to infiltrate tissues to minimize such pain. We reported that pain elimination could be improved by preventing saliva from flowing into areas where topical anesthetics are applied. ${ }^{7)}$ However, the ability of commercially available products to eliminate pain was limited by needle insertion. Thus, topical anesthetic formulations offering favorable intra-oral retentivity were prepared and clinically evaluated in the present study.

Agar and gelatin are widely used as bases for novel topical anesthetic formulations prepared in hospital pharmacies, ${ }^{8-10)}$ but the gelatin concentrations obviously vary according to the type of formulation. We applied a gelatin concentration of $10 \%$ in our formulations with reference to that used in oral gummy formulations. We analyzed the agar concentration with reference to internal formulations ${ }^{10)}$ as reports describing this type of topical formulation are scarce. Since solidification was sufficient at a concentration of $\geq 1 \%$, we established an agar concentration of $1 \%$ for agar-based formulations.

Current gelatin-based formulations for intra-oral applications are made to melt in the oral cavity and the subsequent absorption of a diluted medicinal substance through the oral mucosa depends on the melting point of gelatin, which is $c a$. $30^{\circ} \mathrm{C}$. In contrast, agar has a higher melting point and it does not dissolve in the oral cavity. However, it adheres poorly to the mucosal surface and thus serves as a matrix base that facilitates the release of drugs. ${ }^{10)}$ We aimed to produce a formulation possessing the characteristics of both bases, namely excellent adhesion to the oral mucosa, a well-preserved appearance and superior drug release. Thereafter, we investigated the melting characteristics at different concentrations of gelatin to determine the optimal ratio of agar and gelatin.

Agar/gelatin-based formulations were prepared on the assumption that their size changes depending on the application site, and that less could be applied compared with existing formulations. In contrast, the size (diameter, $7 \mathrm{~mm}$; adhesion area, $38.5 \mathrm{~mm}^{2}$ ) of commercially-available formulations for the oral patch, Copalon ${ }^{\circledR} 6 \%$ topical anesthetic solution for dental use and the Aftach $^{\circledR} 25-\mu \mathrm{g}$ patch for the oral cavity, cannot be changed. Thus, we prepared smaller agar/gelatin-based formulations. However, variations in the test results might increase as the size of the formulations decreases. Thus, we tested formulations prepared in 5-mm cubes with an adhesion area of $25 \mathrm{~mm}^{2}$. The thickness of the formulations was set at $2 \mathrm{~mm}$ based on the 2-mm-thick sponges for the Coparon ${ }^{\circledR} 6 \%$ topical anesthetic solution. The amount of time required for complete melting at $37^{\circ} \mathrm{C}$ decreased as the gelatin compounding rate increased. In addition, the shape was retained after heating for a specific period as the gelatin compounding rate decreased. Therefore, heating for $3 \mathrm{~min}$ melted the formulation when the gelatin concentration was $\geq 3 \%$, but the shape persisted under these conditions when the gelatin concentration was $\leq 2 \%$. We set the gelatin concentration of the agar/gelatin-based formulation at $2 \%$ based on these findings. Since the melting point and hardness of the agar/gelatin-based formulation can be adjusted by changing the ratio of the agar/gelatin mixture, various formulations can be prepared corresponding to the usage.

Needle insertion of the agar/gelatin-based formulations was significantly deeper than that achieved with the existing formulations. When this formulation was applied, the injection needle could be painlessly inserted to a mean depth of $5 \mathrm{~mm}$ or deeper. In actual clinical practice, drugs are generally injected into a region at an about 2-mm depth, and the effect of topical anesthesia was evaluated by inserting an injection needle into a 1-2-mm depth using VAS in many reported studies. ${ }^{1,4,5)}$ However, since this formulation enables painless insertion of an injection needle to a mean depth of $5 \mathrm{~mm}$ or deeper, it was difficult to use VAS for comparison of the analgesic effect among the formulations at the general depth of injection needle insertion. Thus, we evaluated the effect of topical anesthesia based on the depth at which the injection needle could be painlessly inserted in the anesthetic-applied region. ${ }^{6}$ Fukuda et al. evaluated the anesthetic effects of laser irradiation and topical lidocaine on the gingivobuccal fold based on the depth of needle insertion and VAS, and found that pain was inhibited in the group with deeper needle insertion. ${ }^{11)}$ Their finding suggests that our analgesic effect evaluation method based on the depth of injection needle insertion is appropriate. It was suggested that the agar/gelatin-based formulation exhibits a superior analgesic effect for insertion of an injection needle and the drug is rapidly absorbed and reaches a deep region. The preparation method of this formulation is relatively simple, but it is not appropriate for preparation at the time of use because it requires heating followed by solidification by cooling. In contrast, we judged that the formulation with a food thickener-base was superior to the commercial formulations, although the pharmacological effect was poorer than that of the agar/gelatin-based formulation. This was because the ability to reduce pain was equivalent to, or better than that of commercial formulations, and the drug did not appear to affect areas where it was not applied. In addition, viscosity was sufficient after only stirring for several minutes after adding drug solution. Therefore, the agar/gelatin-based formulation is appropriate for preparation at the time of use when sufficient time is available and a deep analgesic effect is necessary, whereas the thickener-based formulation is appropriate in more urgent situations and a deep analgesic effect is not necessary.

The new topical anesthetic formulations prepared herein use bases that are included in foods and are thus very safe. In addition, the anesthetic used to prepare the formulations has traditionally served as a general pharmaceutical product. The method of preparation does not require specific equipment, and the procedures are simple, which will allow general dental clinics to prepare the formulations easily. The appearance and size of agar/gelatin-based formulations varies depending on the application area or disease, whereas the viscosity of thickener-based formulations can vary according to the individual preferences of dental practitioners. Consequently, the new topical anesthetic formulations may be applied in a wide range of clinical settings. Since the formulations were prepared at the time of use with no decomposition control, preservation was not investigated. Thus, we cannot discuss the shelf life and safety of formulations. Since the novel topical anesthetic formulations were useful, decomposition controls such as sterilization methods and preservatives must be investigated with the aim of clinical application. The reduction of pain generated by injected drug solutions should also be investigated.

This study evaluated the applicability of novel topical formulations as pre-anesthetic medication in dental practice. 
However, these formulations can be applied to eliminate pain during various types of treatments and to treat oral lesions, since their appearance and size can be adjusted, and intra-oral retentivity is excellent. This suggests that the new topical anesthetic formulations will be beneficial in the clinical setting. The formulations prepared in this study will contribute to painless dental treatment and an improved QOL for patients with oral lesions.

\section{CONCLUSION}

The new topical anesthetic formulations showed an excellent analgesic effect against pain associated with needle insertion. As the users are able to change the size and form according to the purpose, the formulations may be used to various clinical situations.

The formulations prepared in this study will markedly contribute to painless treatments and an improved QOL in patients suffering from oral lesions in future dental practice.

Conflict of Interest The authors declare no conflict of interest.

\section{REFERENCES}

1) Fukayama H, Sunakawa M, Mori M. Researches of enhancement of topical anesthesia in dentistry. JJADS, 20, 80-85 (2001).

2) Akiyama A, Nagoh T, Sano K, Kanri T. Evaluation of topical anesthetic activities of several agents using starch wafer method. J. Jpn. Dent. Soc. Anesthesiol., 33, 43-49 (2005).

3) Ishii T, Nakanishi O, Fujimoto A, Sakamoto E, Yamamuro T, Fukui
I, Kou F, Fuushuku H, Koba H, Horiuchi N, Nishi M. The effects on the pain of infiltration anesthesia at the canine mucobuccal region by different concentrations of topical anesthesia. J. Kyushu Dent. Soc., 49, 533-538 (1995).

4) Koshiba K, Kasahara H, Hosaka K, Ogasawara T, Watanabe T. A study of painless local anesthesia: effects of topical anesthetics and nitrous oxide. J. Jpn. Dent. Soc. Anesthesiol., 23, 711-722 (1995).

5) Watanabe T, Koshiba K, Okuda H, Koshi I, Hosaka K, Ogasawara T, Kasahara T. Comparison of the pain perception induced by intraoral penetration by a new fine needle and a 30 -gauge needle. J. Jpn. Dent. Soc. Anesthesiol., 23, 19-30 (1995).

6) Ogasawara T, Sairenji N, Kawase Y, Ohtsuki Y, Ohtsuki M, Takai T, Hosaka K, Kasahara H. A study of the effectiveness of topical anesthetic (60\% lidocaine tape) on the oral mucous membrane. $J$. Jpn. Dent. Soc. Anesthesiol., 30, 36-41 (2002).

7) Ando T, Shimoo Y, Nakasato M, Yoshida H. Clinical evaluation of superficial anesthetic products to mitigate pain due to injection of local anesthetic into the gingival. Oral Therap. Pharmacol., 31, 53-61 (2012).

8) Yoshida H. Sublingual immunotherapy. Jpn. J. Rhinol., 45, 87-89 (2006).

9) Namiki N, Takagi N, Yuasa H, Kanaya Y. Preparation of gummi drug using gelatin. Yakuzaigaku, 57, 86-94 (1997).

10) Kaneuchi M, Sawaguchi R, Kohri N, Senbongi K, Sakai H, Asano $\mathrm{M}$, Iseki K. Evaluation of preparation of ketamine in hospital for practical use - analysis of plasma concentration profiles of ketamine and norketamine after oral and buccal administration-. JJSPC, 13, 18-22 (2006).

11) Fukuda $T$, Matsui $K$, Yoshida $T$, Akashi G, Yuasa M, Yamaguchi H, Gomi K, Arai T. Effect of Nd:YAG, Er:YAG laser irradiation on gingival surface anesthesia. J. Jpn. Soc. Laser Dent., 17, 118-122 (2006). 